\title{
The Effect of Peer Tutoring in Physical Education for Middle School Students with Severe Disabilities
}

\author{
Aija Klavina, Ph.D., Karina Rodionova \\ Academy of Sport Education of Latvia
}

This study assessed the effect of peer tutoring on physical, instructional and social interaction behaviors between middle school age students with severe and multiple disabilities (SMD) and peers without disabilities. Additional measures addressed the activity time of students with SMD. The study was conducted in inclusive general physical education settings under two instructional support conditions for students with SMD: (a) teacher-directed, and (b) peer-mediated. During teacherdirected conditions students with SMD had frequent interactions with education personnel while interactions with peers were minimal. When peer -mediated conditions were implemented, the interactions between target students and trained peer tutors increased, however, data did not present stability and clear trend. The trained peer tutors delivered fewer instructions during intervention than teachers during baseline. The activity engagement time did not change across the two conditions for both students with SMD. The social interactions remained low throughout the study.

Key words: peer tutoring, severe and multiple disabilities, physical education

Physical education (PE) implements physical education curricula and instruction that emphasizes enjoyable participation in physical activity and helps students develop the knowledge, attitudes, motor and behavioral skills, and confidence needed to improve physical fitness and adopt and maintain physically active lifestyles (CDC, 2008). In middle school students are expected to experience positive, challenging and enjoyable physical activities while learning skills and developing an understanding of the benefits and importance of physical activity. In conjunction with these activity experiences, students develop a positive self-image and social skills that will provide personal competence in work and leisure situations. Furthermore, high-quality physical education is both developmentally and instructionally relevant for all students, including those with disabilities (NASPE, 2007). Moreover, researchers (Cotton, 1995; McKenzie, Marshall, Sallis \& Conway, 2000; Wehmeyer \& Agran, 2006) have indicated that teachers should engage in a variety of teaching behaviors to increase quality of student learning and recognize students' development as well as their individual differences. For example, providing frequent opportunities to respond (e.g., error corrections, providing feedback to a peer).

The No Child Left Behind Act (NCLB) and the reauthorization of the Individuals With Disabilities Education Improvement Act 2004 (IDEA 2004) require teachers to use researchbased practices and instructional arrangements when including students with disabilities in their classes (Odom et al., 2005). This is challenging when teaching students with severe and multiple disabilities (SMD) in physical education (PE). First, there is limited research-based information on how to include students with SMD in physical education. While special education literature provides rich set of studies on how to meet students' with SMD education needs in classroom arrangement (Cushing \& Kennedy, 1997; Cushing, Clark, Carter, \& Kennedy, 2005; Jackson, Ryndak, \& Wehmeyer, 2008/2009), the active nature of the learning environment in 
a gym or sport field significantly differs from classroom settings. Second, these students typically have poor cognitive, social, motor development, or adaptive behavior skills (Hunt, Alwell, Farron -Davis, \& Goetz, 1996), therefore, it is challenging for them to learn skills and knowledge required in middle school PE class (e.g., play basketball in the team) (Block 1992).

Participation is central concept in inclusive education, however the definition of "inclusion" is not so easily stated and therefore debated (Armstrong \& Spandagou 2011; Hedegaard, 2012). For example, Law et al. (2007) have formulated participation in activities as the context in which children form friendships, develop skills and competencies, express creativity, achieve mental and physical health, and determine meaning and purpose in life. Furthermore, Brown and Gordon (1987) have indicated that children with disabilities tend to be more restricted in their participation than their peers and the gap widens as they become adults. Regarding teaching and peer culture in middle schools the dynamics of peer relationships and the nature of teacher instructional delivery vary considerably from what students encountered in elementary school (Rubin, Bukowski, \& Laursen, 2009). Evans, Salisbury, Palombaro, Berryman, and Hollywood (1992) found that social acceptance is not associated only with students' intellectual functioning, but it is more affected by the learning environment where education services are provided. Furthermore, Goodwin and Watkinson (2000) found that factors contributing to participation and positive experience for students with physical disabilities in general physical education (GPE) were a sense of belonging and companionship.

The process of students teaching their peers is one of the oldest forms of collaborative learning. Several studies have indicated that peer tutoring can be used as effective instructional accommodation to improve academic outcome of students with disabilities
(Houston-Wilson et al., 1997; Lieberman et al., 1997, 2000; Murata \& Jansma, 1997) and increase interactions between peers with and without severe disabilities (Klavina \& Block, 2008) in inclusive PE. As indicated above, regarding peer tutoring for students with SMD, many special education studies have explored peer support instructional arrangements to increase students' with SMD engaged time and academic success in classroom setting (Hudson, Browder, \& Wood, 2013; Okilwa, 2010). The research on peer support provided for students with SMD in inclusive PE has been minimal. However, the results from special education studies done in classrooms (Greenwood et al., 2002; Hudson et al., 2013; Yun -Ching, Carter, $\&$ Sisco, 2013) are in line with adapted physical education studies demonstrating more frequent interactions between peers and students with SMD during peer tutoring than during teacher instruction (Klavina, 2008; Klavina \& Block, 2008).

This study aimed to explore the effect of instructional accommodation of peer tutoring on interaction behaviors between middle school students with and without severe and multiple disabilities in inclusive physical education.

Method

Participants and Setting. Two middle school students with severe and multiple disabilities participated in this study. To select target students, purposive sampling design (Goetz \& Le Compte, 1984) was used including students who were (a) representative of persons with SMD, (b) participated in GPE sessions with support of adult personnel (e.g., APE instructor, teacher assistant), and (c) expected to increase participation in $\mathrm{PE}$ activities with age appropriate peers as indicated in their Individual Education Plan (IEP) for physical education (IEP-PE). In this study students with SMD were addressed as Jimmy and Carl (pseudonyms). Both target students attended special education classroom for more than $60 \%$ of their school day. 
Jimmy was 14 years old boy with cerebral palsy (spastic tetraplegia), mild intellectual disability and very limited vocabulary. He needed physical assistance in all activities during GPE class (e.g., following directions, participating in individual tasks, or games). Jimmy used automatic wheelchair to move around. His current IEP-PE objectives included goals related to his participation in GPE activities together with peers given moderate verbal and physical assistance. Carl was 12 years old boy with severe cerebral palsy and intellectual disabilities. He also had severe speech difficulties. His current IEP-PE goals included objectives related to gross motor skills and participation in collaborative games with peers without disabilities. Classmates seemed to like him, although it was challenging for them to do activities together, or to communicate with Carl. He had iPad communication board attached to his wheelchair handle to interact with others. Carl liked to show photos and "talk" to classmates using text messages available on the screen. Sometimes teacher assistant removed the iPad from Carl's chair because he was more interested in iPad than to follow instructions provided by teacher. Both target students received related services, speech and language therapy, physical therapy and occupational therapy. Both students with SMD were included in the GPE class for full time. However, often they came about 10 -15 minutes late to gym and/or had to leave earlier because of their individual schedule and needs (e.g., longer lunch time, toileting, school bus schedule).

Five general education students served as peer tutors (two for Jimmy and three for Carl). To select peer tutors, the general physical educators were asked to identify students who they perceived would work well with the target student and were willing to provide support during PE. Although, no other criteria were used for selecting potential peer tutors, teachers considered peers who had interacted with student with SMD in the past. All selected peers agreed when asked.

All students received the parents consent forms. In addition, they were required to have parental permission to be video recorded.

The GPE classes taught by GPE teachers were 90 minutes in length and held two to three times per week for each class. Class sizes were about 20-25 students. The GPE program was based on fitness components and skills progression on each unit organized for 1 - 2 weeks. For example, the soccer unit, then athletics, and then followed by baseball unit. The classes consisted 10-15 minutes of the warm-up period, 50 - 60 minutes of the main part, and 10 -15 minutes of games and teachers' feedback at the end of class. The APE service in this study was provided by two graduate students and special education personnel (three teacher assistants) who also assisted students with SMD throughout their school day.

The collaboration between GPE teachers, the researcher and assistance personnel during GPE classes differed among target students. Carl's teacher assistant collaborated with the researcher in identifying target skills and initiating Carl's interactions with peers. Also, the general PE teacher planned PE sessions so that Carl could involve and be part of the team or group work. Jimmy had two teacher assistants during study. The one collaborated with the researcher in initiating and monitoring interaction behaviors between peer tutors and Jimmy, while the other did not present much interest in this study and had little to no contact with the researcher. Also, his general PE teacher did not make a strong effort to provide activities facilitating opportunities for Jimmy to interact with peers.

\section{Peer Tutor Training}

The both groups of peer tutors received three 20 minutes training sessions. They were organized before PE class at the gym. The peer tutor training sessions were adopted from the model used by Klavina and Block (2008). The 
content was changed appropriate to middle school students' age. For example, it included topics on how to adapt and modify PE activities to facilitate meaningful participation of the student with SMD; how to address the peer with SMD IEP-PE goals within the activity in the physical education class; how to provide prompts and frequent, positive feedback; and how to facilitate interactions with other students in the class in ways that provide alternatives to dependence on paraprofessionals (Reardon, 2008). During first sessions the researcher explained students the study project and what will be their role in it. Then, they discussed what it means to be a peer tutor and how he/or she should behave. Also, rules and roles of being a peer tutor were discussed (e.g., being friendly, talk softly, and providing praises). At the end of session confidentiality and safety issues were explained. All peer tutors received peer tutor manual and were encouraged to read it at home. The second and third session was organized during GPE sessions including the student with SMD. The researcher notified the teaching personnel (GPE teachers, teacher assistants) that peer tutors and the student with SMD will be assigned to work together at some activities during PE. For example, when all students practiced basketball drills, the researcher asked peer tutors to assist Jimmy in throwing the soft- ball in the hula-hoop in front of him. One peer tutor held the hula-hoop while other passed balls back to Jimmy. The researcher reminded tutors to follow the five TIP-TAP (Tips for Teaching, Assisting and Practicing, Klavina \& Block, 2008) steps from the manual: (1) instructions (e.g., cues, prompts), (2) demonstration, (3) physical assistance, (4) feedback, and (5) error correction. The peer tutor training implemented in GPE activities provided students with and without disabilities opportunity to interact appropriate to the real GPE class situation.

\section{Dependent Variables}

The primary dependent variables were instructional, physical and social interaction behaviors between students with SMD and their peers, and teaching personnel across two study phases: (1) teacher directed, and (2) peermediated conditions. Physical interaction behaviors encompassed one-to-one interactions related to the GPE activities, or IEP-PE objectives for student with SMD. Instructional interaction behaviors were any verbal, or nonverbal instructions received from/or directed to other(s) in order to complete the task related to GPE (e.g., prompts, demonstration of the task, providing error correction, providing assistance). Social interaction behaviors included verbal or nonverbal communication on content not related to GPE (e.g., talking about TV shows, or after school activities, or discussing pictures on the students' with SMD iPad). While social behaviors were not related to the GPE, they might affect social acceptance and relationships between students with SMD and their peers without disabilities (Block \& Malloy, 1998; Sherrill, Heikinaro-Johansson, \& Slininger, 1994). In addition, the data of activity engagement time for the two target students with SMD was obtained and analyzed.

\section{Experimental Design and Data Collection}

To evaluate the effect of the peer tutoring intervention, a single subject multiple baseline research design across participants was used (Gast, 2010). The experimental design included two phases: (1) baseline, or teacher directed, and (2) intervention, or peer- mediated phase. It should be noted that few (1-2 PE classes) prebasline sessions were used in each research site to allow participants an opportunity to become familiar to a researcher with a camera before starting the data collection. To determine effect of peer tutoring, the intervention was implemented across students and the mean, level, and trend changes in interaction behavior outcomes were defined. In addition, the activity engagement time for the two target students was compared between the two instructional conditions.

In this study data were collected for a total of 25 GPE sessions (11 for Jimmy and 14 for Carl). 
The length of each observation session was about 40 minutes. All observation sessions were collected on videotapes with the use of the SONY Digital Handycam. The student with SMD wore a wireless microphone to enable the first author to monitor interaction behaviors.

During teacher-directed (i.e., baseline) conditions the teacher assistant or APE students provided assistance to students with disabilities applying the same instructional strategies they used with their students before the study. No additional instructions were given to teachers, thus, data were obtained from intact inclusive GPE sessions. During peer-mediated instructional conditions the APE teacher or teacher assistant initiated tutoring procedures assigning the peer tutor(s) to assist the student with SMD. Then, he or she monitored tutoring activities from about a 3-5 $\mathrm{m}$ distance. Also, it was ensured that each peer tutor provides help to the student with SMD for about 10-15 minutes so that none of the tutors would get tired or overwhelmed during the tutoring process. Then other tutor took turn, or teacher involved other students (volunteers) willing to help the target student. Otherwise, the teacher assisted the target student. The peer support depended on class content, ability level of students and other characteristics that might influence students' performance. Peer tutors were reminded to call for teachers' help if they did not know how to adapt activity or had questions about tutoring procedure. The APE teacher prompted the peer tutor to interact with the student with SMD if no interactions were occurring for about 20 seconds during the tutoring period. The teacher praised both the peer tutor and the student with SMD on successful partnership and collaboration to help maintain students' confidence and enjoyment during tutoring (Cole, 1988; Logan et al., 1998). In addition, ongoing feedback was provided to peer tutors after each GPE class to correct interaction behaviors and improve the ways they provided teaching instructions.

\section{Data Analyses}

The Computerized Evaluation Protocol of Interactions in Physical Education (CEPI-PE) (Klavina \& Block, 2008; Klavina, 2011) was used to analyze the video sessions. The tool is a computer based observations schedule with 24 variables classified in three subcategories: (1) instructional, (2) physical, and (3) social interactions. The CEPI-PE categorical variables have been validated for its use in inclusive GPE setting (Klavina, 2011). In this study dependent measures included the physical, instructional and social interaction behaviors between teachers, students with and without disabilities. The mean percentage of combined interaction behaviors between students with and without disabilities in GPE was measured across two instructional conditions. The five-second observation and five-second record partial interval system was applied. The obtained data were analyzed based on percentage mean scores. To identify the effect of intervention the Improvement Rate Difference (IRD) was calculated. The IRD is defined as the improvement rate (IR) of the treatment phase(s) minus the improvement rate of the baseline phase(s): IRT $-I R B=I R D$ (Cochrane Collaboration, 2006; Sackett, Richardson, Rosenberg, \& Haynes, 1997). Very small and questionable effects scores about $50 \%$ and below. Moderate-size effects have IRD scores of around $50 \%$ to $70 \%$. Effects rated as large and very large generally have IRD scores of $70 \%$ or $75 \%$ and higher (Parker, Vannest \& Brown, 2009). In addition, differences in interaction behaviors for participants across study conditions were compared by the Wilkoxon test. Data analysis was performed using SPSS version 20.0 for Windows. Statistical significance was set at $\mathrm{p}<.05$.

\section{Reliability}

Inter observer agreement was assessed with a trained second observer for an average of $30 \%$ $(28 \%-32 \%)$ of all observations. A second observer, graduate student in adapted physical 
activities, independently observed and recorded data. Point-by-point agreement was calculated by dividing the number of agreements by the number of agreements plus disagreements and multiplying by $100 \%$. Overall, the mean and range of percentage agreement across participants was $95.5 \%(92.1 \%-100 \%)$.

\section{Social Validity}

After concluding the study, the researcher conducted survey with the GPE teachers, the teacher assistants, the graduate APE students, and peer tutors. The purpose of the survey was to obtain information on teacher's and GPE students' opinions of the peer tutoring study. This information was intended be used to improve peer-tutoring strategies with students with SMD in GPE and plan future research studies.

\section{Results}

During GPE periods under teacher-directed instructional conditions (i.e., baseline) the scores for interaction behaviors between students with and without SMD and teachers were variable (Figure 1, A- B). The mean percentage of intervals when Jimmy had interactions with the adult teaching personnel (e.g., teacher assistant or APE student) was 71.8 $\%$ (range, $62.0 \%-79.0 \%$ ), while interactions with prospective peer tutors was only $4.3 \%$ (range, .0\%-12.2\%) and with other peers 2.4 $\%$ (range, $.0 \%-7.5 \%$ ). The mean percentage of intervals when Carl had interactions with the adult teaching personnel during baseline also was higher than interactions with not trained peer tutors and other peers $(\mathrm{M}=45.5 \%$. range, $12.5 \%$ - $68.2 \% ; \mathrm{M}=18.0 \%$, range, $.0 \%$ $32.5 \% ; \mathrm{M}=16.7 \%$, range, $10.0 \%-34.2 \%$, respectively). However, Carl had more interactions with peers than Jimmy. This variability may be attributed to the alternating involvement of random general education students in interactions with students with SMD in each site. In contrast, the interaction behaviors with adult support personnel were high for both target students (range, $12.5 \%$ to $79.0 \%$ ). It should be noted that obtained data did not include intervals when there were no interactions performed by the observed participant (e.g., waiting time).

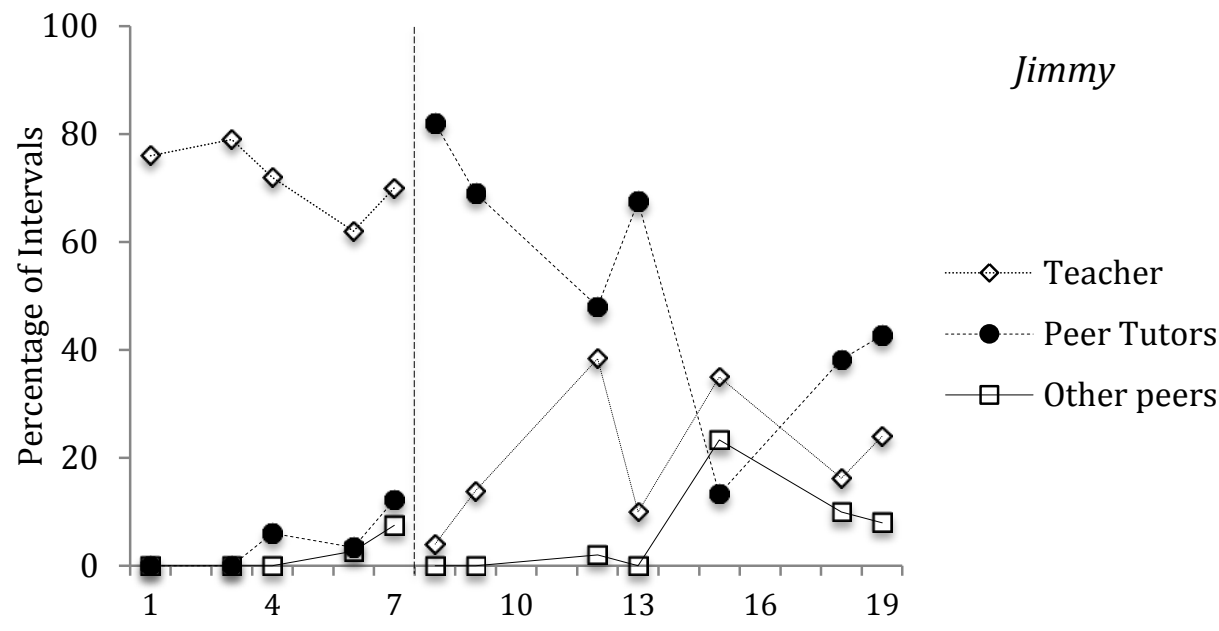

Figure 1(A). Percentage of intervals when Jimmy interacted with teacher, peer tutors, and other peers across teacher-directed and peer-mediated instructional conditions. 


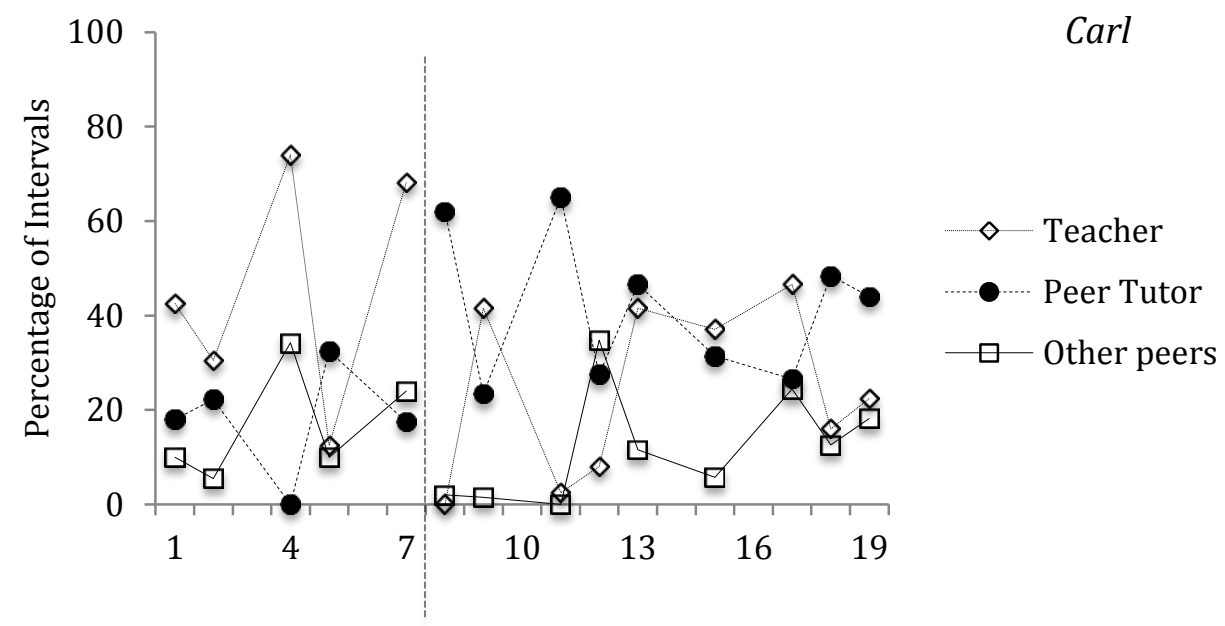

Figure $1(B)$. Percentage of intervals when Carl interacted with teacher, peer tutors, and other peers across teacher-directed and peer-mediated instructional conditions.

Figure 1(A,B) illustrates that at beginning of the intervention phase introduction of peermediated instructional conditions resulted in an immediate increase in interaction behaviors with peer tutors for both target students. However, these data patterns did not present stability and predictability throughout the intervention sessions. For Jimmy there was visibly high frequency of interactions with peer tutors during first part of intervention while it regressed towards end of the study. The mean percentage of intervals when Jimmy was involved in behavior interactions with trained peer tutors was $51.5 \%$ (range, $13.3 \%-82.0 \%$ ). Carl's data trends for scores of interactions with peer tutors during intervention were fairly flat, however, presenting higher level comparing to the baseline. The mean percentage of intervals when Carl was involved in behavior interactions with trained peer tutors was $41.6 \%$ (range, 23.4 $\%-65.0 \%)$. Furthermore, mean scores for interaction behaviors between students with SMD and other peers were slightly higher during peer-mediated than in teacher-directed conditions. For Jimmy the mean percentage of intervals in interactions with other peers was 6.1 $\%$ (range, .0 \% - $23.3 \%$ ), while for Carl the mean score was $12.3 \%$ (range, .0\% $-34.8 \%$ ) that was lower than in baseline $(\mathrm{M}=16.7 \%)$.
For both target students interaction behaviors with adult support personnel was significantly lower in intervention than in baseline phase. For Jimmy the mean score was $20.2 \%$ (range, $4.0 \%$ to $38.4 \%$ ) and for Carl $23.9 \%$ (range, .0 \% $46.6 \%$ ). Students and teachers in this study did not provide any negative social interactions. The social interaction behaviors between target students, peer tutors and teachers remained low throughout the study (range, .08\% - 16. 7\%) indicating minimal interactions not related to GPE content among participants.

Figure 2 illustrates instructional interaction behaviors (e.g., providing prompts, physical assistance, feedback) demonstrated by education personnel and peer tutors. While during intervention instructional behaviors significantly increased for peer tutors of Jimmy and Carl (M $=29.5 \%$ and $\mathrm{M}=9.1 \%$, respectively), they were less frequent than instructions provided by teachers during baseline. The number of instructions provided to Carl by peer tutors and teachers during both study conditions (range, .0 $\%-20 \%$ for peer tutors; and range, $2.0-27.2 \%$ for teachers). Overall, there was not significant difference between mean percentage of instructions provided by teachers during baseline and peer tutors during intervention across the two research sites $(\mathrm{p}<.05)$. 


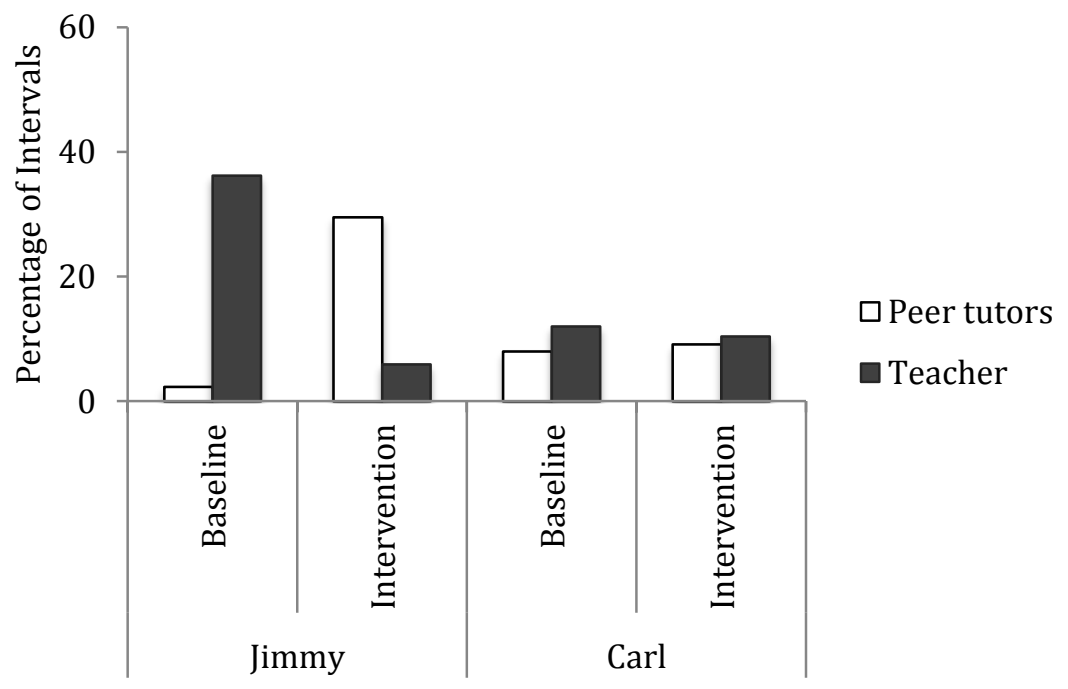

Figure 2. Mean percentage of intervals in instructional interactions for peer tutors and teachers across teacher-directed and peer-mediated instructional conditions.

Activity Engagement Time

Figure 3 illustrates that Jimmy and Carl maintained similar percentage of activity engagement time throughout baseline and

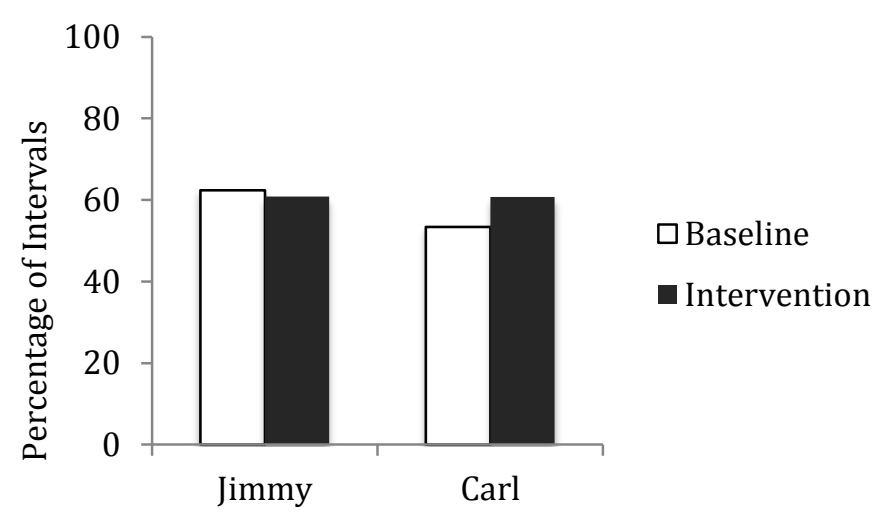

Figure 3. Mean percentage of intervals in active engagement time for students with SMD across teacherdirected and peer-mediated instructional conditions.

\section{The Improvement rate difference}

The Improvement rate difference (IRD) scores for interaction behaviors of students with and without disabilities between baseline and intervention conditions are presented in Table 1. For Jimmy the gain in improvement rate for interaction behaviors with peer tutors from the baseline to the intervention was $100 \%$ gain, which is significant level of change, while with intervention phase $(62.4 \%-60.8 \%$ and $53.4 \%$ $60.7 \%$, accordingly). The Wilcoxon test reported not significant change in results across study phases $(\mathrm{p}>.05)$. other peers the gain in interaction improvement rate was only $2 \%$ indicating not significant change. For Carl the gain in improvement rate for interaction behaviors with peer tutors from the baseline to the intervention was $40 \%$ gain, which is not significant level of change. The gain in interaction improvement rate with other peers also was not significant (IRD $=22 \%$ ). 
Table 1. IRD scores for interaction behaviors between study conditions

\begin{tabular}{lcc}
\hline & $\begin{array}{c}\text { Interactions with } \\
\text { Peer Tutors }\end{array}$ & $\begin{array}{c}\text { Interactions with } \\
\text { other peers }\end{array}$ \\
\hline Jimmy & $100 \%$ & $2 \%$ \\
\hline Carl & $40 \%$ & $22 \%$ \\
\hline
\end{tabular}

\section{Social Validity}

Six teachers and five peer tutors involved in this study completed their surveys. Three teachers (two general PE teachers and one teacher assistant) indicated that study was beneficial for students with SMD improving their independence, increasing interactions with classmates and providing more access to needed support. However, all teachers reported that it was evident that students with SMD enjoyed being assisted by their classmates from the beginning of intervention sessions. One challenge cited by Jimmie's teachers related to his involvement in interaction behaviors with other peers indicating limited improvement. Regarding peer tutors' performance, teachers reported positive acceptance of classmates with SMD. Carl's teachers indicated that his peers provided spontaneous and natural positive interactions toward Carl, while Jimmie's peers interacted with him when directed by the teacher to do so. Some teachers commented "it was a positive experience for all students." When asked about the applicability of peer tutoring for students with SMD in GPE setting, all teachers' responses were in agreement that it was feasible to implement the intervention in GPE environment, however, should be planned earlier and implemented from beginning of the school year. Finally, teachers recommended that peer tutoring should involve more peer tutors so that each general education student would have a chance helping the classmate with SMD.

When peer tutors were asked about their experience in the study, all of them reported personal benefits, recognizing contributions of peers with disabilities, a greater understanding of persons with severe disabilities, and improved social skills. Three tutors reported that they did not know about peer tutoring before this study. Some tutors anecdotally noted that during study they realized that their classmate with SMD was capable "of doing many things together with other classmates." When asked to indicate the most challenging experience, Jimmie's tutors mentioned their worries with some safety aspects for Jimmy. All five tutors indicated that they would like to participate in peer tutoring activities in future.

\section{Discussion}

This study demonstrated the effect of peer tutoring on the interaction behaviors between middle school students with and without SMD in inclusive GPE setting. The significance of such studies rests with the fact that peer interactions and peer acceptance become increasingly important as students approach adolescence (Cassidy \& Asher, 1992), and disabilities in school-age children are associated with long-term negative personal and vocational outcomes (Edgar \& Levine, 1987; Sitlington, Frank, \& Carson, 1991, 1992).

The data of interaction behaviors collected under teacher-directed (baseline) conditions indicated high level of interactions between Jimmy and adults ranging $62.0 \%$ to $79.0 \%$, while for Carl data were variable, ranging from $12.5 \%$ to $68.2 \%$. Anecdotal notes indicated that Jimmy often was taken to side of the gym to work on individual skills with the teacher assistant. For example, while other general education students practiced volleyball drills, teacher assistant gave Jimmy softball and ask him to hit it into empty trashcan. They did this activity for about 15 minutes while none of 
peers interacted with Jimmy. These findings are consistent with other studies including students with SMD in classroom (Carter et al., 2010; Chan et al., 2009) and in GPE setting (Klavina \& Block, 2008). Authors have noted that prolonged close proximity of adult support personnel adversely affect interactions between students with and without disabilities while at the same time increase social isolation and loss of independence for students with disabilities (Causton-Theoharis \& Malmgren, 2005; Giangreco et al., 1997, 1999, 2001). Moreover, in many cases teacher assistant decided about activities for Jimmy according what she observed other students were doing. Also, she had limited or no communication with the GPE teacher on how to modify and adapt GPE activities for Jimmy's needs to make his participation more inclusive. These observations supported findings of other authors reporting that paraeducators lack training and knowledge on how to involve the student with disabilities in GPE activities (Maurer, 2004) while GPE teachers have indicated that they are not inadequately prepared and/or lacking support and resources to effectively teach students with more severe disabilities (Hodge, Amman, Casebolt, Lamaster, \& O'Sullivan, 2010). In contrast, Carl's classmates, including prospective peer tutors, occasionally interacted with him during baseline and continued provide positive interactions throughout the study. Also, the teacher assistant encouraged random peers to be Carl's partners initiating interaction behaviors between students.

When peer-mediated conditions containing trained peer tutor intervention were initiated, interaction behaviors between target students and peer tutors raised immediately across the two research sites (see Figure 1, A-B). The visual inspection of graphed data for Jimmy revealed that data points of the peer-mediated condition did not overlapped with those of the teacher-directed conditions indicating significant level of change (IRD $=100 \%$ ). However, these findings should be addresses with caution since intervention data line did not present stability and clear trend. While Jimmie's peer tutors were involved in frequent interactions with him during first three intervention sessions, collaboration between students regressed as study progressed. This might be explained by the variability in the content (e.g., group activities, or assessment) and environment (e.g., indoor vs. outdoor) of GPE sessions that affected interactions. Anecdotal notes indicated that at the beginning of intervention the GPE teacher used more collaboration directed activities in small groups contributing implementation of peer tutoring procedures. However, at later stage of intervention she planned skill assessments as end of semester approached that limited opportunities for tutors to interact with Jimmy. Also, anecdotal notes indicated that peer tutors joined Jimmy in activities only when directed by the assistant teacher or researcher. The visual inspection of graphed data for Jimmy revealed that in some sessions, where the score for interactions with peer tutors was low, the score for interactions with teacher was high or vice versa indicating the behavior interaction rates between the teacher assistant and tutors. In contrast to Klavina \& Block (2008) research, this study presented low interactions between Jimmy and other peers throughout the study (IRD $=2 \%)$. Other studies have indicated that, while middle school students are willing to form friendships with peers with severe disabilities, they might not know how to behave in the company of a peer with a severe disability. Hendrikcson et al. (1996) recommended that friendship between students with and without severe disabilities should be facilitated through teacher accommodations, facilitative teaching styles, and a facilitative school climate.

For Carl the mean percentage of intervals in interactions with peer tutors during intervention was lower than for Jimmy $(\mathrm{M}=41.6 \%$ and $\mathrm{M}=$ $51.5 \%$, respectively). Although, the level remained higher than in baseline, the data were inconsistent throughout the study and did not 
present clear trend. However, Carl had more interactions with other peers than Jimmy $(\mathrm{M}=$ $12.3 \%, \mathrm{M}=6.1 \%$, respectively). Furthermore, the visual inspection of graphed data for Carl revealed that part of the data points of the peermediated condition overlapped with those of the teacher-directed conditions. The IRD scores indicated not significant level of change between Carl and peer tutors $($ IRD $=40 \%)$ and other peers $($ IRD $=22 \%$ ) across the two study conditions. However, these results should not be perceived as negative study outcome. The anecdotal notes indicated that general education students in this class demonstrated positive attitudes and desire to help the peers with disabilities. Also, this class included two other students with moderate and mild disabilities. The APE teacher or teacher assistant often asked random general education students to assist these students while he/ or she was helping Carl. Students and teachers did not demonstrate any negative social interactions in this study. According Klavina and Block (2008) the Model of Multiple Component Interaction in inclusive GPE, the use of peers as a natural support may be one way to utilize individualized goals of the students with SMD, and facilitate natural interaction behaviors between peers with and without SMD.

In contrast to previous studies on peer tutoring for elementary school age students with SMD in GPE (Klavina 2008; Klavina \& Block, 2008), the peer tutors delivered fewer instructions during intervention than teachers during baseline. However, there was not significant difference between the mean percentage of instructions provided by teachers during baseline and peer tutors during intervention across the two research sites ( $\mathrm{p}<$ $.05)$. Also, the findings in this study did not support outcomes of special education research by Odom et al. (1992) indicating that teachers used more prompts and reinforcement at the beginning of the peer support intervention, while later the teachers' involvement gradually decreased. For example, Carl's teacher assistant maintained about the same level of instructions throughout the study. This might be explained by the fact that introduction of peer tutoring was new instructional accommodation for all participants, including education personnel, and it might take more time for teachers to get used to the new teaching strategies.

The activity engagement data showed not significant change in results for target students across teacher-directed and peer - mediated conditions. The support provided by trained peer tutors and other classmates did not adversely affect activity engagement level for students with SMD overall. While these findings did not support other studies reporting increase in the activity engagement time for students with disabilities under peer-mediated support conditions (Huoston-Wilson et al., 1997; Klavina \& Block, 2008; Lieberman et al., 1997, 2000; Murata \& Jansma, 1997), the results indicated that peer tutoring did not have adverse impact on academic performance of students with SMD.

\section{Limitations and Implications for Future} Research

There were several limitations noted in this study. First, the small accessible population restricted the sample selection from the "larger" pool of students with SMD included in GPE class. The further research is needed to investigate effects of the peer tutoring intervention across a wider variety of participants, settings, and age groups. The study outcome indicated that during intervention sessions Jimmy increased interaction behaviors with peer tutors, while interactions with other peers were low. The future studies should focus on key components of participation while implementing peer-mediated accommodations in inclusive GPE session. Also, the future research could replicate this study investigating if specific teacher and student context variables (e.g., teaching culture, peer culture) influence the effectiveness of peermediated strategies. Another limitation was 
related to the time of a school year (second half) and activities used during GPE sessions during study. The outcomes of the study utilizing peer tutoring across GPE sport program in prolonged time period (e.g., from beginning of the school year) might have been different.

This study did not focus on academic skill acquisition measures demonstrated by tutors and tutees. As noted by authors (i.e., Murata \& Jansma, 1997; Lieberman et al., 1997, 2000), implementation of peer tutoring strategies in the GPE class did not adversely affect, and even improved (Lieberman et al., 2000) the academic skills for both peer tutors and tutees. Future studies should investigate the relationship between the academic achievements and interaction behaviors for students with and without disabilities as the result of peer tutoring interventions.

\section{References}

Armstrong, D., Armstrong, A.C., Spandagou, I. (2011): Inclusion: by choice or by chance? International Journal of Inclusive Education, 15:1, 29-39

Block, M.E. (1992). What is appropriate physical education for students with the most profound disabilities? Adapted Physical Activity Quarterly, 9, 197-213.

Brown M, Gordon WA. (1987) Impact of impairment on activity patterns of children. Archives of Physical Medicine and Rehabilitation, 68, 828-832.

Carter, E. W., Moss, C. K., Hoffman, A., Chung, Y.-C., \& Sisco, L. (2011). Efficacy and social validity of peer support arrangements for adolescents with disabilities Exceptional Children, 78(1), 107-125

Cassidy, J., \& Asher, S.A. (1992). Loneliness and peer relations in young children. Child Development, 63, $350-365$.

Causton-Theoaris, J.N., \& Malmgren, K.W. (2005). Increasing peer interactions for students with severe disabilities via paraprofessional training. Council for Exceptional Children, 71(4), 431-444.

Center of Disease Prevention and Control (2008). School Based Physical Education. Working with schools to increase physical activity among children and adolescents in physical education classes. An Action Guide. http://www.prevent.org/actionguides

Chan, J. M., Lang, R., Rispoli, M., O'Reilly, M., Sigafoos, J., \& Cole, H. (2009). Use of peer-mediated interventions in the treatment of autism spectrum dis- orders: A systematic review. Research in Autism Spectrum Disorders, 3, 876-889.

Cochrane Collaboration. (2006). Cochrane handbook for systematic reviews of interventions. Retrieved August 24, 2013, from

http://www.cochrane.org/index_authors researchers.htm

Cole, D.A.(1988). Difficulties in relationships between nonhandicapped and severe mentally retarded children: The effect of physical impairments. Research in Developmental Disabilities, 9, 55-72.

Cotton, J. (1995). The Theory of Learning. London: Kogan Page Cushing, L. S., \& Kennedy, C. H. (1997). Academic effects of providing peer support in general education classrooms on students without disabilities. Journal of Applied Behavior Analysis, 30, 139-151.

Cushing, L. S., Clark, N. M., Carter, E. W., \& Kennedy, C. H. (2005). Access to the general education curriculum for students with significant cognitive disabilities. TEACHING Exceptional Children, 38(2), 613.

Donaldson, R.M., Helmstetter, E., Donaldson, J., \& West, R. (1994). Influencing high school students attitudes toward an interactions with peers with disabilities. Social Education, 58 (4), 233 - 237.

Edgar, E., \& Levine, P. (1987). A longitudinal follow-along study of graduates of special education. Seattle: University of 
Washington EEU, Child Development and Mental Retardation Center.

Evans, I.M., Salisbury, C.L., Palombaro, M.M., Berryman, J., \& Hollywood, T.M. (1992). Peer interactions and social acceptance of elementary age children with severe disabilities in an inclusive school. Journal of the Association for Persons with Severe Handicaps, 17(4), $205-212$.

Gast, D. L. (2010). Single subject research methodology in behavioral sciences. NewYork, NY: Routled Giangreco, M.F., Edelman, S.W., Luiselli, T.E., \& MacFarland, S.Z. (1997). Helping or hovering? Effects of instructional assistant proximity on students with disabilities. Exceptional Children, 64, 7 -18

Goetz, J.P. \& Le Compte, M.D. (1984). Ethnography and qualitative design in education research, New York: Academic Press.

Goodwin, D.L., \& Watkinson, E.J. (2000). Inclusive physical education from the perspective of students with physical disabilities. Adapted Physical Activity Quarterly, 17, 144-160.

Greenwood, C.R., Maheady, L., \& Delaquadri, J. (2002). Classwide peer tutoring programs. In M.R. Shinn, H.M. Walker \& G. Stoner (Eds.) Interventions for academic and behavior problems II: Preventive and remedial approaches (pp.611-649). Bethesda, MD: National Association of School Psychologists.

Hedegaard, H. J. (2012): Limits to inclusion. International Journal of Inclusive Education, 16(1), 89-98.

Helmstetter, E., Peck, C.A., \& Giangreco, M. (1994). Outcomes of interaction with peers with moderate or severe disabilities: statewide survey of high school students. Journal of the Association for Persons With Severe Handicaps, 19 (4), 263-276.

Hodge, S., Ammah, J., Casebolt, K., Lamaster, K., \& O'Sullivan, M. (2004). High school general physical education teachers' behaviors and beliefs associated with inclusion. Sport Education and Society, 9(3), $395-419$.

Houston-Wilson, C., Dunn, J.M., Van der Mars, H., \& McCubbin, J. (1997). The effect of peer tutors on motor performance in integrated physical education classes. Adapted Physical Activity Quarterly, 14, 298-313.

Hudson, M.E., Browder, D.M., \& Wood, L.A. (2013). Review of experimental research on academic learning by students with moderate and severe intellectual disability in general education. Research and Practice for Persons with Severe Disabilities, 38(1), $17-29$.

Hunt, E., Alwell, M., Farron -Davis, F., \& Goetz, L. (1996). Creating socially supportive environments for fully included students who experience multiple disabilities. Journal of the Association for Persons with Severe Handicaps, 21(2), 5371.

Klavina, A. (2008). Using peer mediated instructions for students with severe and mulitple disabilities in inclusive physical education: A multiple case study. European Journal of Special Needs Education, 1 (2), 7-19.

Klavina, A. (2011). Development and Initial Validation of the Computerized Evaluation Protocol of Interactions in Physical Education. Measurement in Physical Education and Exercise Science, 15(1), 2646.

Klavina, A. \& Block, M. (2008). The effect of peer tutoring on interaction behaviors in inclusive physical education. Adapted Physical Activity Quarterly, 25, 132-158.

Law, K., King, G., King, S., Kertory, M., Hurley, P., Rosenbaum, P., Young, N., \& Luttropp, A., \& Granlund, M. (2010). Interaction - it depends- a comparative study of interaction in preschools between children with intellectual disability and children with typical development. 
Scandinavian Journal of Disability Research, 12 (3), 151 - 164.

Lieberman, L.J., Newcomer, J., McCubbin, J., \& Dalrymple, N. (1997). The effects of cross age tutors on the academic learning time in physical education of children with disabilities in inclusive elementary physical education classes. Brazilian Journal of Adapted Physical Education \& Recreation, 4, 15-32.

Lieberman, L.J., Dunn, J.M., Mars, H., \& McCubbin, J. (2000). Peer tutors' on activity levels of deaf children in inclusive elementary physical education. Adapted Physical Activity Quarterly, 17, 20-39.

Logan, K.R., Jacobs, H.A., Gast, D.L., Murray, A.S., Daino, K., \& Skala, C. (1998). The impact of typical peers on the perceived happiness of children with profound multiple disabilities. The Journal of the Association for Persons with Severe Handicap, 23, 309-318.

McKenzie, T.L., Marshall, S.J., Sallis, J.F. \& Conway, T.L. (2000). Student activity levels, lesson context, and teacher behavior during middle school physical education. Research Quarterly for Exercise and Sport, 71(3), $249-259$.

Maurer, K. (2004). The use of paraprofessionals in general physical education. Unpublished master's thesis. State University of New York - Brockport.

Murata, N.M., \& Jansma, P. (1997). Influence of support personnel on students with and without disabilities in general physical education. Clinical Kinesiology, 51 (2), 3746.

National Association for Sport and Physical Education. (2007). Initial guidelines for online physical education: A position paper from the National Association for Sport and Physical Education. Reston, VA: Author.

Odom, S.L., Brantlinger, E., Gersten, R., Horner, R. H., Thompson, B., \& Harris, K. (2005). Research in special education: Scientific methods and evidence-based practices. Exceptional Children 71(2), 137148.

Okilwa, N.S. (2010). The effect of peer tutoring on academic performance of students with disabilities in grades 6 through 12: a synthesis of the literature. Remedial and Special Education, 31(6), 450 - 463.

Parker, R.I., Vannest, K.J., \& Brown, L. (2009). The improvement rate difference for single - case research. Council for Exceptional Children, 75(2), $135-150$.

Reardon, R.S. (2008). The impact of formal classwide peer support training on the occurrence of initiated and reciprocal peer interactions of students with significant disabilities in inclusive physical education classes. Unpublished doctoral dissertation, University of Central Florida.

Rubin, K. H., Bukowski, W. M. \& Laursen, B. (Eds.). (2009). Handbook of peer interactions, relationships, and groups. New York. NY: Guilford Press.

Sackett, D. L., Richardson, W. S., Rosenberg, W., \& Haynes, R. B. (Eds.). (1997). Evidence-based medicine: How to practice and teach EBM. London: Churchill Livingstone.

Sitlington, P, Frank, A., \& Garson, R. (1991). Transition of adolescents with behavioral disorders-Is it successful? Behavioral Disorders, 16, 180-191.

Sitlington, P., Frank, A., \& Garson, R. (1992). Adult adjustment among high school graduates with mild disabilities. Exceptional Children, 59, 221-233

Yun-Ching, C., Carter, E.W., \& Lynn, Sisco, L.G. (2013). A systematic review of interventions to increase peer instructions for students with complex communication challenges. Research and Practice for Persons with Severe Disabilities, 37(4), 271 $-287$.

Wehmeyer. M., \& Agran. M. (2006). Promoting access to the general curriculum for students with significant cognitive disabilities. In F. Spooner \& D. Browder 
(Eds.). Teaching reading, math and science to students with significant cognitive disabilities (pp. 15-37). Baltimore: Paul H. Brookes.
Wentzel, K.R., Barry, C.M., \& Caldewell, K.A. (2004). Friendship in middle school: Influences on motivation and school adjustment. Journal of Educational Psychology, 96, 195-203. 